\title{
Middleware for the Integration of Hospital Information Systems
}

\section{Leila Shahmoradi1 $\oplus^{\oplus}$, Mahdi Habibi-Koolaee ${ }^{*} \oplus$, Maryam Ebrahimi $^{3}$, Fatemeh Parnian Khoy4 ${ }^{\oplus}$, Ahmad Soltani $^{5}$}

1- Department of Health Information Management, Faculty of Allied Medical Sciences, Tehran University of Medical Sciences, Tehran, Iran.

2- Health Management and Social Development Research Center, Golestan University of Medical Sciences, Gorgan, Iran

3- MSc in Health Information Technology, Ferdows Faculty of Paramedicine, Birjand University of Medical Sciences, Birjand, Iran

4- Faculty of Allied Medical Sciences, Tehran University of Medical Sciences and Health Management and Economic Research Center, Iran University of Medical Sciences, Tehran, Iran

5- Health Information Management Research Center, Tehran University of Medical Sciences, Tehran, Iran.

\section{ABSTRACT}

Introduction: The integration of healthcare information systems is one of the most urgent priorities of healthcare organizations. Middleware has a major role in the integration of hospital information system (HIS). The purpose of this study is to determine the type of middleware used, their configuration and integration approaches in the hospitals of the research community.

Material and Methods: This study was descriptive in nature and was conducted in the form of a survey, with data being gathered via a selfstructured questionnaire, in 2014. Seventeen hospitals affiliated to TUMS that have the HIS were recruited for this study. The questionnaire consisted of three parts. Simple statistical analysis was used to determine the integration status of HISs.

Results: The most striking result to emerge from the data is that $64.7 \%$ of HISs had database-oriented middleware. Approximately half of surveyed HISs (41.2\%) used synchronous mechanism and almost two-thirds of them $(70.2 \%)$ used web service. Although, $17.2 \%$ of HISs use service-oriented integration approach, but the overall response to this question was poor.

Conclusion: The result of the study indicates that the database-oriented middleware facilitate accessibility of the databases, on a variety of platforms. It might be related to the variety of company those developed the HISs. The result showed that the using web services could be helpful to application integration. The results of this investigation show that the HIS companies and healthcare facilities must be considered to the standards of interoperability for development and selection of the systems. Further research should be done to investigate the integration status of HISs in cross-national level and with other information systems in the field of healthcare.

(i) Please cite this article as:

Shahmoradi L, Habibi-Koolaee M, Ebrahimi M, Khoy FP, Soltani A. Middleware for the integration of hospital information systems. Iran J Med Inform. 2017; 6(1): 28-32. DOI: $\underline{10.24200 / \text { ijmi.v6i1.141 }}$

\footnotetext{
* Corresponding Author: M Habibi-Koolaee, Health Management and Social Development Research Center, Golestan University of Medical Sciences, Gorgan, Iran (Email: habibi@goums.ac.ir)

Article History

Received: 2017-10-21

Accepted: 2017-11-28

Published: 2017-12-20

\section{Keywords}

Computer software applications Hospital Information Systems

Information Systems Systems Integration 


\section{INTRODUCTION}

In the healthcare, Hospital Information Systems (HIS) are used to facilitate the management of clinical, financial and administrative information in the hospital and designed to enhance quality of care1. Integrating hospital information systems is very difficult, but necessary. Only in this way that the computerized hospital information systems can be the advanced tools to achieve clinical goals. These should have the specifications of comprehensiveness, integrity, reliability and security, ergonomic quality, comfortable and usability for all user levels [1-7].

Design and implementation of a comprehensive hospital information system with desired functionality and standard, leading to the integration of electronic medical systems [8]. Integrity means that the data collected from multiple units of the hospital or related clinic/center are maintained in the unified database. Information about an admitted patient in the each unit of the hospital (if permitted), is accessible. Integrity is not limited to the patient information, but includes all the processes of the hospital [?].

Although the hospital information systems are used in most health care organizations, but these are often not integrated. The data are incomplete and inconsistent and information flow is discontinuous, because the focus of these protocols is to transfer of data, not on the integration and synchronization $[10,11]$. In addition to the internal differences of the hospital, which is due to different activities and different workflows, the external communication of hospitals, also effects on the extent and complexity of the HIS. To establish communications among hospitals, an integrated system is required [12].

Users as a major client of a system, has logical expectations. These expectations include access to all the provided services, simplify and without intra-organizational restrictions and without limitation of place. It is clear that these expectations are not possible without cooperation and mutual influences in different parts of the system to provide services to users.

In fact, one of the slogans of the system is to access to all services from one unit, would not be possible without applying of integration in the different procedural and administrative levels. To access the integration in the administrative area, use of standards and software architecture is required. Moreover, the framework integration can help the adoption of HIS [13].

Generally, the integration must be considered in the following areas:

- Administrative and functional including strategic decisions, organizational units and processes.

- Technical and non-functional including applications and databases.

Much effort has been made to build integration between disparate systems within health care organizations [14-16]. Some have defined the standardized interface for the object-oriented services in the healthcare domain (the Common Object Request Broker Architecture or CORBA is an example that allow sharing of activities such as access and control between different systems) $[15,17]$.

Azami et al. stated that data, functions and workflows are the fundamental factors for integration of a system. Due to the complexity of clinical data in terms of the number and type, backing up all in one storage is not a good solution for heterogeneous systems. In this case, the middleware can function as a virtual data center for all clinical data. According to Azami et al. functional integration can be performed through a set of web services [2]].

Liu Jing Yong et al, defined middleware as a tool for integration of the healthcare system and classified middleware according to the communication models into four different categories, including: procedural, message-oriented, transaction and object middleware [18].

Web services as a distributed middleware, is an ideal solution for the interoperability problems of system that referred by Zhang et al. [19].

Batta and Mukherjee stated that web service technologies have been proposed in response to some interoperability challenges of heterogeneous health information systems (HIS). They also stated that service oriented architecture based on message is a pragmatic approach to solve integration problems of HIS [20].

Most important steps to integrate hospital information systems, including to Perform a complete analysis to understand various aspects of the system, Understanding the function of the system components and the relationship between them to achieve a basis for designing and implementing a suitable and efficient system [21].

Data have store separately in the separate information systems. Hence, to obtain comprehensive information about the organizational activity, an integrated system is needed [22]. On the other hand, resistance to integration of information systems is one of the main reasons for the failure of the systems [23]. Also, integration of data provides complete information about the patient status [24].

This study aimed to determine the types of middleware configuration, the types of applied middleware, application integration methods and to determine the integrity of hospital information systems in the affiliated hospitals of Tehran University of Medical Sciences (TUMS).

\section{MATERIAL AND METHODS}

This was a descriptive study that investigated the status of application integration in the hospitals, performed in 2014. Statistical population included the affiliated hospitals of TUMS, which had a HIS. Seventeen hospitals investigated.

Data were collected using a self-structured questionnaire. The design of the questionnaire was based on a literature review of journal articles, books and other available library resources about integration tools and techniques. For gathering data, we interview HIS handlers in the hospitals. The questionnaire consists of three parts. The first part deal with demographic information about participants, including six closed questions such as name, position and specialty of interviewee. The second part of the questionnaire consists of information about hospital information systems in terms of the name of the developer and supporter companies, subsystems of the HIS and the relation among them with six closed and semi-open questions. Finally, the third part of the questionnaire deal with the integration of HISs with 19 questions (close and open). For instance, the type of middleware used by HIS, the kind of middleware configuration, the communication mechanism and the application integration approaches. Descriptive statistics used to analysis the results.

The participants were informed about the objectives of the study and were informed that the results of the study will be published by maintaining trusteeship.

\section{RESULTS}

In this study, we used the hospital information systems data from 17 hospital affiliated to TUMS. According to the research findings, the majority of hospital uses the HISs and the company that has developed the system, it is responsible for the support of the system. Six types of HISs from different companies were used in these 
hospitals, including the Rahavard Rayaneh (3), Tirajeh Rayaneh (6), Pooya Samaneh Diva (2), Rayavaran (4), KianTech (1) and Farabi (1).

The frequency distribution of subsystems in the HISs in the affiliated hospitals of TUMS shown in Fig 1. It seems that the need for an integrated information system in admission and discharge, laboratory and pharmacy units have been feeling more than other sectors. 15 participants stated that all of information systems can exchange data together.

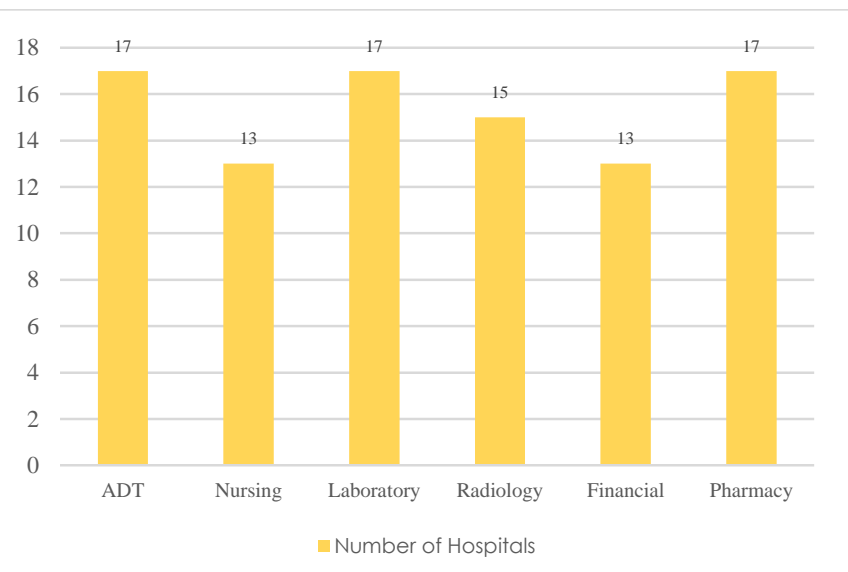

Fig 1: Frequency distribution of subsystems in hospital information systems (ADT: Admission, Discharge and Transfer)

According the result of the study, 78\% of the middleware used in affiliated hospital of TUMS had many-to-many configuration and other had a point-to-point configuration.

As shown in Table 1, the most widely used middleware in hospitals of the study is database-oriented middleware that used for integration of information systems.

Table 1: Frequency of middleware used in hospital information systems of study

\begin{tabular}{|l|l|l|}
\hline Middleware Call & Frequency & Percentage \\
\hline $\begin{array}{l}\text { Remote Procedure 17 } \\
\text { RPC) }\end{array}$ & 47.1 \\
\hline $\begin{array}{l}\text { Message-Oriented } \\
\text { Middleware (MOM) }\end{array}$ & 2 out of 17 & 11.8 \\
\hline Distributed objects & 5 out of 17 & 29.4 \\
\hline $\begin{array}{l}\text { Database- oriented } \\
\text { middleware }\end{array}$ & $\begin{array}{l}11 \text { out of } \\
17\end{array}$ & 64.7 \\
\hline Transactional middleware & 5 out of 17 & 29.4 \\
\hline Integration servers & 3 out of 17 & 17.6 \\
\hline
\end{tabular}

It can be seen from the data in Table 2 that synchronous communication mechanism is the most commonly used, because it had the added value for the hospital in terms of time saving and increasing the quality. Also, $70 \%$ of hospital, used the capability of web based services. In terms of HIS architecture, $23.5 \%$ of hospitals had a three-layer architecture.
Table 2: Frequency of middleware communication mechanism, web-service usage and architecture in hospital information systems of study

\begin{tabular}{|c|c|c|c|}
\hline Core & Subset & 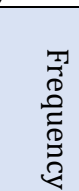 & 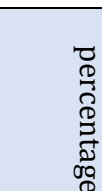 \\
\hline \multirow{5}{*}{$\begin{array}{l}\text { Middleware } \\
\text { communication } \\
\text { Mechanism }\end{array}$} & Synchronous & 7 & 41.2 \\
\hline & asynchronous & 3 & 17.6 \\
\hline & Hybrid & 3 & 17.6 \\
\hline & Not Specified & 4 & 23.6 \\
\hline & Total & 17 & 100 \\
\hline \multirow{4}{*}{$\begin{array}{l}\text { Web-Service } \\
\text { usage }\end{array}$} & Yes & 12 & 70.6 \\
\hline & No & 2 & 11.8 \\
\hline & Not Specified & 3 & 17.6 \\
\hline & Total & 17 & 100 \\
\hline \multirow{8}{*}{$\begin{array}{l}\text { HIS } \\
\text { Architecture }\end{array}$} & Open & 1 & 5.9 \\
\hline & 7 layer & 1 & 5.9 \\
\hline & Multi-layer & 2 & 11.8 \\
\hline & 3 layer & 4 & 23.5 \\
\hline & Client server & 1 & 5.9 \\
\hline & Stare & 2 & 11.8 \\
\hline & Not Specified & 6 & 35.2 \\
\hline & Total & 17 & 100 \\
\hline
\end{tabular}

As Table 3 shows, $35.3 \%$ of hospital had the capability of data exchange with other hospitals, while approximately the same amount $(29.4 \%)$ had not.

Table 3: Frequency of capability to data exchange with other systems outside of hospital (SEPAS: Persian abbreviation for electronic health record system of Iran, MOH: Ministry Of Health)

\begin{tabular}{|l|l|l|}
\hline & Frequency & Percentage \\
\hline Had capability & 6 & 35.3 \\
\hline Don`t had capability & 5 & 29.4 \\
\hline Only to SEPAS & 2 & 11.8 \\
\hline Only to MOH & 1 & 5.9 \\
\hline Not Specified & 3 & 17.6 \\
\hline Total & 17 & 100 \\
\hline
\end{tabular}

As the result shown, according to the participants view, the most appropriate approach of application integration is the service oriented approach (Table 4).

Table 4: Frequency of application integeration approaches for hospital information systems according to participants view

\begin{tabular}{|l|l|l|}
\hline Application integration approach & Frequency & Percentage \\
\hline Information-oriented & 1 & 5.9 \\
\hline $\begin{array}{l}\text { Business Process Integration- } \\
\text { Oriented }\end{array}$ & 2 & 11.8 \\
\hline Service-Oriented & 3 & 17.6 \\
\hline Portal-Oriented & 0 & 0 \\
\hline Not specified/ Not Known & 11 & 64.7 \\
\hline Total & 17 & 100 \\
\hline
\end{tabular}




\section{DISCUSSION}

The present study was designed to determine the types of middleware and integration methods of HISs in affiliated hospital of TUMS.

Many-to-many middleware is the most powerful middleware logical model and the best option for the application integration, because it provides both flexibility and applicability to the application integration problem domain [25]. On the other hand, point-to-point middleware has an inability to properly bind more than two applications. To exchange information in this scenario, applications must be connected and information must be exchanged by a shared centralized server $[9,25]$. With regard to the foregoing, as much as possible, we should avoid the point-to-point integration, unless no other option is available or a naive solution is required [26]. However, this study showed that the most hospitals use the many-to-many middleware configuration.

As defined by the Griffen, database-oriented middleware is a technological function that enables access to databases of different types, on different platforms and/or in multiple locations [27]. Morris et al. stated that the database-oriented middleware facilitates communication with databases through means such as Web Services, XML and by various connectivity standards such as product- specific, open database connectivity (ODBC) and Java database connectivity (JDBC) [28]. In this study the most hospitals use the database-oriented middleware. The most HISs of the study uses heterogeneous databases and have various platforms. It seems that this could help the integration of HISs.

Using synchronous and asynchronous mechanisms enables the organizations to integrate applications. In most organizations, both mechanisms are applied. In synchronous, the middleware is entirely dependent to the applications. This means that other applications must be stopped to do a process. In asynchronous, the applications are not dependent on others to do a process. Hence, as Puschmann and Alt stated, the asynchronous mechanism is the best method for application integration [29]. The results of this study indicates that about half of the HISs used the synchronization mechanism. This finding had conflict with Puschmann and Alt's study [29].

The result of the study indicates that the most HISs uses three layer architecture that is consistent with Winter et al. study that proposed a graphical three layer architecture for hospital information systems. According their states this architecture can be useful to strategic information management [30]. However, Hasselbring stated that middleware integration address the syntactic level and enterprise application integration addresses the semantic levels. There is no borderline between them, for example the CORBA architecture deployed for middleware integration, but addresses the enterprise application integration [31].

Regarding the interactivity of systems through web services, can be hoped that the hospitals were directed to use this feature. As Zhang et al. indicated, the web service, as a distributed middleware is an ideal solution for interactivity of systems [19]. The study result showed that the hospitals tend to use the web services.

These findings of the current study are consistent with those of Chung et al. who found the service-oriented application integration is seamless whether it is done within the organization or across organizations [32]. As Gu and Zhang's study showed the service-oriented integration approach can ease the composition of existing services and coordination new business process [33].

\section{CONCLUSION}

This paper has investigated the integration status of HISs in affiliated hospitals of TUMS. The findings of this study suggest that the HIS companies and hospitals must be considered to the standards of data exchange and interoperability for developing and selecting the systems. It was also suggested that the treatment protocols and clinical workflow must be clarified.

These findings enhance our understanding of the status of middleware to integrate HISs in affiliated hospitals of TUMS. We can use these findings in future decision making for information technology infrastructure.

The current study was limited by the cooperation of the participants. Some of the questionnaire items were not fulfilled. Further cross-national work need to be done to determine the role and status of middleware for integration of HISs and other systems in the healthcare domain.

\section{REFERENCES}

1. Degoulet P, Fieschi M. Physiological signal processing. introduction to clinical informatics: Springer; 1997.

2. El Azami I, Malki MOC, Tahon C. Integrating Hospital Information Systems in Healthcare Institutions: A Mediation Architecture. J Med Syst. 2012; 36(5): 3123-34. PMID: 22086739 DOI: 10.1007/s10916-011-9797-8 [PubMed]

3. Safdari R, Dargahi H, Shahmoradi L, Farzaneh Nejad A. Comparing four soft wares based on ISO 9241 part 10. J Med Syst. 2012; 36(5): 2787-93. PMID: 21755414 DOI: 10.1007/s10916-011-9755-5 [PubMed]

4. Ahmadi M, Shahmoradi L, Barabadi M, Hoseini F. A survey of usability of hospital information systems from the perspective of nurses, department secretaries, and paraclinic users in selected hospitals: 2009. Journal of Health Administration. 2011; 14(44): 11-20 .

5. Safdari R, Dargahi H, Shahmoradi L. Survey of quality ergonomic of Iran's hospital information system and comparison with three other software from users' point of view. Journal of Hospital. 2010; 9(1): 33-42 .

6. Shahmoradi L, Ahmadi M, Haghani H. Determining the most important evaluation indicators of health care information systems (HCIS) in Iran. Health Inf Manag. 2007; 36(1): 1322. PMID: 18195393 [PubMed]

7. Ahmadi M, Shahmoradi L, Barabadi M, Hoseini F. Usability evaluation of hospital information systems based on IsoMetric 9241. Hakim Health Sys Res. 2011; 13 (4): 226233.

8. Ferrara FM. The standard 'healthcare information systems architecture' and the DHE middleware. Int J Med Inform. 1998; 52(1-3): 39-51. PMID: 9848401 [PubMed]

9. Wreder K, Deng Y. Architecture-centered enterprise system development and integration based on distributed object technology standard. Computer Software and Applications Conference, $1999 . \quad$ IEEE. 10.1109/CMPSAC.1999.812712

10. Larbi E, Edwards JW, Badidi E. An exploration of demographic inconsistencies in healthcare information environments. In:

11. Wickramasinghe N, Geisler E, eds. The encyclopedia of healthcare information systems. Vol 2. Idea Group Inc. (IGI). 2008: 561-572 .

12. Meyer M, Levine WC, Brzezinski P, Robbins J, Lai,F, Spitz G, et al. Integration of hospital information systems, operative and peri-operative information systems, and operative 
equipment into a single information display. AMIA Annu Symp Proc. 2005; 2005: 1054. PMID: 16779341 [PubMed]

13. Esmahi L, Badidi E, Edwards JW. Managing demographic data inconsistencies in healthcare information systems. International Journal of Information Systems and Social Change. 2010; 1(1): 56-72. DOI: 10.4018/jissc.2010092905

14. Ahmadi H, Nilashi M, Shahmoradi L, Ibrahim O. Hospital Information System adoption: Expert perspectives on an adoption framework for Malaysian public hospitals. Computers in Human Behavior. 2017;67:161-189. doi:https://doi.org/10.1016/j.chb.2016.10.023

15. Lopez DM, Blobel BG. A development framework for semantically interoperable health information systems. Int J Med Inform. 200; 78(2): 83-103. PMID: 18621574 DOI: 10.1016/j.ijmedinf.2008.05.009 [PubMed]

16. Ko L-F, Lin J-C, Chen C-H, Chang J-S, Lai F, Hsu K-P, et al. HL7 middleware framework for healthcare information system. e-Health Networking, Applications and Services conference. IEEE. 2006; 1: 50-165. DOI: 10.1109/HEALTH.2006.246437

17. Cosimo F. The integration of hospital information systems through user centered design. Sheffield, Sheffield Hallam University; August 1994.

18. Sujansky WV, Overhage JM, Chang S, Frohlich J, Faus SA. The development of a highly constrained health level 7 implementation guide to facilitate electronic laboratory reporting to ambulatory electronic health record systems. J Am Med Inform Assoc. 200; 16(3): 285-90. PMID: 19261950 DOI: $10.1197 /$ jamia.M2610 [PubMed]

19. Jingyong L, Yong Z, Yong C, Lichen Z. Middleware-based distributed systems software process. Proceedings of the International Conference on Hybrid Information Technology. Daejeon, Korea. 2009; 345-348.

20. Zhang J, Xu W, Ewins D. System interoperability study for healthcare information system with web services .Journal of Computer Science. 2007; 3(7): 515-22.

21. Batra U, Mukharjee S. National healthcare information system integration: A service oriented approach. International Journal of Computers. 2011; 3(5): 354-61.

22. Siamak M. Need for integration of information systems in hospitals through the implementation of a comprehensive management information system (MIST). Proceeding of First National Conference on Resource Management in Hospital. 2003; Tehran.

23. Awad EM. Management information system: Concept, structure, and applications. Menlo Park, Calif.: BenjaminCummings Pub Co; 1988.

24. Sumner M. Critical success factors in enterprise wide information management systems projects. Proceedings of the ACM SIGCPR conference on Computer personnel research. 1999; New York.

25. Tsumoto S, Hirano S, Kawamura T. Statistical estimation of software quality in hospital information system. In: Sawatani Y, Spohrer J, Kwan S, Takenaka T, eds. Serviceology for smart service system: Selected papers of the 3rd International Conference of Serviceology. Tokyo: Springer Japan; 2017: 341-350.

26. Linthicum DS. Next generation application integration: from simple information to Web services. Boston: AddisonWesley Longman; 2004.

27. Gulledge T. What is integration? Industrial Management \& Data Systems. 2006; 106(1): 5-20. DOI: 10.1108/02635570610640979

28. Morris H, Lee S, Shan E, Zeng S. Information integration framework for product life-cycle management of diverse data. J. Comput. Inf. Sci. Eng. 2005; 4(4): 352-58. DOI: 10.1115/1.1818684

29. Puschmann T, Alt R. Enterprise application integration-the case of the Robert Bosch Group. Proceedings of the 34th Annual International Conference on System Sciences, 2001. IEEE. Hawaii. DOI: 10.1109/HICSS.2001.927242

30. Winter A, Brigl B, Wendt T. Modeling hospital information systems (Part 1): The revised three-layer graph-based meta model 3LGM2. Methods Inf Med. 2003; 42(5): 544-51. PMID: 14654889 [PubMed]

31. Hasselbring W. Information system integration. Communications of the ACM. 2000; 43(6): 32-38. DOI: $10.1145 / 336460.336472$

32. Chung S, Tang LH, Davalos S. A web service oriented integration approach for enterprise and business-tobusiness applications. Web Information Systems-WISE 2004: Springer; 2004:510-515.

33. Gu C, Zhang X. An SOA based enterprise application integration approach. Proceeding of Third International Symposium on Electronic Commerce and Security (ISECS), 2010; Shanghai. 